\title{
Tracking the healing process of experimental liver injuries treated with different sealants and adhesive biomaterials: An evaluation of matrix metalloproteinase.
}

José M. Lloris-Carsí, MD PhD1; Carlos Barrios, MD PhD2; José M. Lloris-Cejalvo, UGS3; Luis GilSantos MD PhD2, Dolores Cejalvo-Lapeña, $\mathrm{PhD}^{3}$

1. Department of Surgery, University of Valencia, Spain

2. Valencia Catholic University, Institute for Research on Musculoskeletal Disorders

3. Division of Experimental Surgery, Valencia Catholic University, Spain email and mailing address of all authors:

Lloris-Carsí, JM jim lloris@mac.com

Department of Surgery, University of Valencia: School of Medicine, Av. Blasco Ibañez 15, 46010

Valencia, Spain,

Barrios, C carlos.barrios@ucv.es

Valencia Catholic University, Institute for Research on Musculoskeletal Disorders

Lloris-Cejalvo, JM josemiguel.lloris@mail.ucv.es

Gil-Santos, L $\quad$ lgil@hilevante.com

Cejalvo-Lapeña, D dolores.cejalvo@ucv.es

Division of Experimental Surgery, Valencia Catholic University, Quevedo 2, 46001 Valencia,

Spain

Financial support: No funding was receive for this work

Author for Correspondence:

Dr. José Miguel Lloris-Carsí,

Department of Surgery, University of Valencia School of Medicine, Av. Blasco Ibañez 15,

46010 Valencia, Spain,

Tel: +34 670070 269;

Fax: +34 963864 805;

Email:jm_lloris@mac.com

\begin{abstract}
This study examines the matrix metalloproteinase (MMP) activity in the healing of liver injuries treated with biological adhesives Tachosil ${ }^{\circledR}$ and GelitaSpon ${ }^{\circledR}$ and the elastic cyanoacrylate Adhflex ${ }^{\circledast}$. Hepatic lesions were induced in male rats using a Stiefel biopsy punch. Healing was assessed 2, 6, and 18 days after injury by quantifying tissue levels of MMP1, 2, 8, 9, and 13. Histopathological repair was evaluated using hematoxylin-eosin, Masson's trichrome, and Periodic Acid Schiff (PAS) staining and immunohistochemical markers CD31 and CD68. The sealants contributed to complete healing. Histopathology and MMP findings indicate that Adhflex ${ }^{\circledR}$ has slower degradation and a strong inflammatory reaction at the onset of healing. Early on, all MMPs showed higher levels in Adhflex ${ }^{\circledR}$ and Tachosil ${ }^{\circledR}$-treated animals, and MMP2 and MMP9 expressions were significantly higher in the Adhflex-treated group at 18 days post-injury (T3). The Adhflex ${ }^{\circledR}$ group had significantly higher MMP8 and MPP13 levels than other treated groups and showed a sustained overexpression of all MMPs, even in the latest healing stages. Notably, the overexpression did not negatively influence the histological healing process. All hepatic trauma injuries should be treated as emergencies, and any easy-to-use and rapid sealant like Adhflex ${ }^{\circledR}$ could be considered as an option for treating liver trauma.
\end{abstract}

Keywords: Hepatic injury, sealants, metalloproteinases, inflammatory response, wound healing. 


\section{Introduction}

Interest in the use of biological adhesives has increased since the creation of Dermabond ${ }^{\circledR}$, which is a cyanoacrylate that is specially designed for clinical use and was approved by the Food and Drug Administration (FDA) in 1998. A variety of biological sealants and adhesives have been applied to control bleeding in cases of hepatic injuries [1-3] and different endoscopic biopsies of solid organs $[4,5]$. The liver has a remarkably ability to self-repair and regenerate following an injury [6].

Liver lesions and regeneration both involve complex pathways related to the extracellular matrix (ECM). The normal degradation of ECM substances like collagen or fibrin is an important feature of tissue repair and remodeling, but irregular ECM turnover contributes to a variety of liver diseases [7]. Matrix metalloproteinases (MMPs) are the primary enzymes involved in ECM degradation during wound healing and also favor cell migration, the buildup of new components in the ECM, and the development and remodeling of regenerative tissue [8].

MMPs not only remodel the ECM but also regulate different immune responses. In addition, they also play significant roles in diverse pathological processes, such as cancer, multiple sclerosis, and some skin disorders [8]. The activity of MMP is regulated based on a combination of production control (such as by Interleukin-1 and TNF- $\alpha$ ), the presence or absence of factors involved in transforming proenzymes into their active forms, and the direct action of tissue inhibitors of MMPs (TIMPs) [9-11].

MMPs are a family of proteases that use zinc-dependent catalysis to break down ECM glycoprotein, which allows cells to move and tissue to reorganize [20]. Currently, there is strong evidence that MMPs play key roles in the healing process, especially during the inflammatory and proliferative phase [10-13]. Consequently, the sampling times used here were defined in line with the inflammatory, proliferative, and maturation stages of injury healing [21]. Most MMPs operate simultaneously and even sometimes share substrates, with the activity of one MMP often causing others to become active. Therefore, comparisons were made between groups of MMPs arranged into defined subfamilies [22].

The involvement of MMP in pathology is more than merely the excessive matrix degeneration or imbalance between MMPs and their specific TIMPs. MMP inhibition may be therapeutically beneficial, and therefore, synthetic MMP inhibitors have been developed and are currently being tested at the clinical level [23]. MMPs and their specific inhibitors (TIMPs) play a pivoting role in both fibrogenesis and fibrolysis in the liver [24].

The clinical usefulness of measuring MMPs continues to expand thanks to advances in new detection methods, which are becoming more objective [12]. The assessment of MMPs is currently uncovering deeper molecular knowledge about the mechanisms of wound healing, but new and improved therapeutic approaches are still needed. A recent investigation found that elevated MMPs in wound fluids from patients with acute traumatic injuries predicted both impaired healing and dehiscence of surgically closed wounds [13]. Some of the roles attributed to MMP in acute and chronic liver injury have been described, but there is a need for further experimentation to improve the understanding of their functions in both physiological conditions and the progression of hepatic disease [14].

As a result of technological developments, the use of tissue adhesives and glues for tissue approximation and hemostasis has increased in surgery [1]. Fibrin sealants are commonly utilized in liver surgery, but their effectiveness in routine clinical practice is not without controversy. Tisseel/Tissucol ${ }^{\circledR}$ and Tachosil ${ }^{\circledR}$ provided the strongest adhesion to liver crosssections in a canine model of hepatectomy [2], and these results may facilitate the optimum 
choice of fibrin sealants for this clinical procedure [1]. Additionally, a multi-center randomized clinical trial evaluated the effectiveness and safety of a fibrin sealant patch in parenchymal bleeding [2]. The results confirmed that the fibrin sealant was safe and highly effective at controlling parenchymal bleeding after hepatectomy, regardless of the type of resection [2].

This study describes changes in MMP expression after the application of three surgical sealants in artificial penetrating hepatic injuries. The study focuses on the activity of MMPs during the healing of liver injuries treated with the biological adhesives Tachosil $^{\circledR}\left(\right.$ TachS$\left.^{\circledR}\right)$, GelitaSpon ${ }^{\circledR} \quad\left(\mathrm{GelSp}^{\circledR}\right)$, and Adhflex $^{\circledR}\left(\mathrm{Adhf}^{\circledR}\right)$ (elastic cyanoacrylate). Histopathological alterations were also controlled during the healing of the hepatic injury and related to MMP activity. The clinical usefulness of measuring MMP expression during the healing of penetrating liver injuries may provide new insights into the repair processes of these lesions and shed light on how liver tissues react to these biological and synthetic adhesives. Adhf ${ }^{\circledR}$ could be considered a useful sealant substance based on the superior adhesion and clotting speed of Adhf ${ }^{\circledR}$ compared with conventional treatments in other organs suggests [14,15].

\section{Results}

\subsection{MMP expression}

Of the MMPs included in the Mosaic ELISA MMP Panel, only MMP1, MMP2, MMP8, MMP9, and MMP13 were sufficiently expressed to be quantifiable (Figure 1, Table 1).

MMP1: Both the time since injury $(p<0.05)$ and the treatment method $(p<0.05)$ influenced the MMP1 expression in the three treated groups according to the Kruskal-Wallis test (Table 1). Along the healing processes (T1, T2, and T3), the untreated group did not exhibit any statistically significant difference in the MMP1 measurements (Table 1, Figure 1-D). The highest mean MMP1 expression level was observed in the group treated with Adhf ${ }^{\circledR}$ at 18 days post-injury (T3). The lowest mean MMP1 concentration in the treated group was observed in the GelSp${ }^{\circledR}$ group (T1), as shown in Table 1.

The Adhf ${ }^{\circledR}$-treated group had the highest MMP1 concentration at 2 days (T1) and 18 days (T3) after the injury. Furthermore, the difference was significantly higher at 18 days (T3) in comparison with the other treatments. The MMP1 values in the Adhf ${ }^{\oplus}$-treated group (3.05 \pm $0.36 \mathrm{pg} / \mathrm{mL}$ ) remained very high in comparison to the other groups (untreated, GelSp${ }^{\circledR}$, and TachS ${ }^{\circledR}$ ) (Table 1, Figure 1 - MMP1).

MMP2: Except for the untreated group, significant differences were found in MMP2 expression between the sampling times of 2, 6, and 18 days post-injury (Kruskal-Wallis test, $\mathrm{p}<0.01$ ) (Table 1, Figure 1). The TachS ${ }^{\circledR}$-treated group had the highest concentration of MMP2 at 6 days after injury (T2 $-4.04 \pm 0.13 \mathrm{pg} / \mathrm{mL}$ ), and the difference was significantly higher than the concentrations exhibited by the other treatments.

MMP8: Like MMP1, both the time since injury and the treatment method influenced the MMP8 expression. Significant differences were detected in MMP8 expression between T1, T2, and T3 $(2,6$, and 18 days post-injury) in the three treated groups $(\mathrm{p}<0.05)$ but not in the untreated group (Kruskal-Wallis test) (Table 1, Figure 1-D). The MMP8 concentration was lowest in the GelSp${ }^{\circledR}$ (T1) group $(0.33 \pm 0.05 \mathrm{pg} / \mathrm{mL})$ and significantly higher in Adhf ${ }^{\oplus}$-treated group (T3) $(1.44 \pm 0.05 \mathrm{pg} / \mathrm{mL})$ (Table 1, Figure 1).

MMP13: The time since injury influenced MMP13 expression in all of the treated groups but not in the untreated animals (Table 1). There were significant differences in MMP13 expression between the untreated group and all three treated groups for most data in Table 1. The Adhf ${ }^{\circledR}$-treated group showed very high levels of MMP13 expression, particularly at T3 (Table 1, Figure 1). 


\begin{tabular}{|c|c|c|c|c|c|c|}
\hline $\begin{array}{l}\text { Liver } \\
\text { MMPs }\end{array}$ & Time & $\begin{array}{l}\text { Untreated } \\
\qquad(n=4)\end{array}$ & $\begin{array}{l}\text { Adhf® } \\
(n=4)\end{array}$ & $\begin{array}{c}\text { GelSp} \AA \\
(n=4)\end{array}$ & $\begin{array}{c}\text { TachS® } \\
(n=4)\end{array}$ & $\begin{array}{c}\text { Kruskal-Wallis } \\
\text { test } \\
\text { (p value) }\end{array}$ \\
\hline \multirow[t]{4}{*}{ MMP 1} & T1 & $0,80 \pm 0,22$ & $2,75 \pm 0,39^{*}$ & $0,35 \pm 0,10^{*} \neq$ & $2,71 \pm 0,31^{*}+$ & 0.005 \\
\hline & $T 2$ & $0,85 \pm 0,09$ & $0,73 \pm 0,06$ & $1,02 \pm 0,10$ & $1,45 \pm 0,08^{*} \pm+$ & 0.005 \\
\hline & T3 & $1,02 \pm 0,16$ & $3,05 \pm 0,36^{*}$ & $0,96 \pm 0,18 \ddagger$ & $1,20 \pm 0,15 \ddagger$ & 0.016 \\
\hline & $\begin{array}{c}\text { Kruskal-Wallis } \\
\text { test ( } p \text { value) }\end{array}$ & $0.234^{n s}$ & 0.021 & 0.024 & 0.008 & \\
\hline \multirow[t]{4}{*}{ MMP 2} & T1 & $1,81 \pm 0,11$ & $3,29 \pm 0,04^{*}$ & $1,16 \pm 0,11^{*} \neq$ & $2,27 \pm 0,06^{*} \pm t$ & 0.003 \\
\hline & $T 2$ & $1,45 \pm 0,09$ & $3,00 \pm 0,14^{*}$ & $2,12 \pm 0,06^{*} \neq$ & $4,04 \pm 0,13^{*} \pm+$ & 0.003 \\
\hline & T3 & $1,55 \pm 0,50$ & $2,72 \pm 0,08^{*}$ & $1,41 \pm 0,07 \ddagger$ & $1,33 \pm 0,08 \ddagger$ & 0.024 \\
\hline & $\begin{array}{c}\text { Kruskal-Wallis } \\
\text { test ( } p \text { value) }\end{array}$ & $0.124^{n s}$ & 0.007 & 0.007 & 0.007 & \\
\hline \multirow[t]{4}{*}{ MMP 8} & $T 1$ & $0,68 \pm 0,09$ & $1,13 \pm 0,25^{*}$ & $0,33 \pm 0,05^{*} \mp$ & $1,28 \pm 0,05^{*}+$ & 0.005 \\
\hline & $T 2$ & $0,91 \pm 0,07$ & $0,62 \pm 0,08^{*}$ & $0,59 \pm 0,15^{*}$ & $1,10 \pm 0,08 \neq t$ & 0.007 \\
\hline & T3 & $0,84 \pm 0,11$ & $1,44 \pm 0,05^{*}$ & $0,78 \pm 0,10 \ddagger$ & $1,10 \pm 0,10^{*} \neq+$ & 0.005 \\
\hline & $\begin{array}{c}\text { Kruskal-Wallis } \\
\text { test ( } p \text { value) }\end{array}$ & $0.076^{n s}$ & 0.015 & 0.012 & 0.037 & \\
\hline \multirow[t]{4}{*}{ МMP 9} & T1 & $1,27 \pm 0.08$ & $1,51 \pm 0,16^{*}$ & $0,34 \pm 0,04^{*} \neq$ & $1,44 \pm 0,05^{*} t$ & 0.005 \\
\hline & $T 2$ & $0,91 \pm 0,13$ & $0,45 \pm 0,14^{*}$ & $0,55 \pm 0,09$ & $0,90 \pm 0,16 \pm t$ & 0.009 \\
\hline & T3 & $0,91 \pm 0,13$ & $1,56 \pm 0,14^{*}$ & $0,77 \pm 0,11 \neq$ & $0,87 \pm 0,13 \ddagger$ & 0.020 \\
\hline & $\begin{array}{c}\text { Kruskal-Wallis } \\
\text { test ( } p \text { value) }\end{array}$ & 0.25 & 0.024 & 0.010 & 0.024 & \\
\hline \multirow[t]{4}{*}{ MMP 13} & $\mathrm{T1}$ & $0,71 \pm 0,06$ & $1,63 \pm 0,16$ & $0,39 \pm 0,04^{*} \neq$ & $1,99 \pm 0,10^{*}+$ & 0.003 \\
\hline & $T 2$ & $0,95 \pm 0,17$ & $1,51 \pm 0,10^{*}$ & $0,90 \pm 0,09^{*} \mp$ & $1,21 \pm 0,10 t$ & 0.008 \\
\hline & T3 & $1,28 \pm 0,08$ & $3,33 \pm 0,19^{*}$ & $1,38 \pm 0,11 \neq$ & $1,82 \pm 0,12^{*} \neq+1$ & 0.003 \\
\hline & $\begin{array}{c}\text { Kruskal-Wallis } \\
\text { test } p \text { value) }\end{array}$ & 0.011 & 0.019 & 0.007 & 0.011 & \\
\hline
\end{tabular}

Table 1. Mean values ( \pm standard deviation) (pg/mL) of metalloproteinases MMP1, MMP2, MMP8, MMP9, and MMP13 at the three healing times (T1: 2 days after injury; T2: 6 days after injury, and T3: 18 days after injury) and in each treatment group. Mann-Whitney U test: $\left(^{*}\right)$ $\mathrm{p}<0.05$ compared with untreated animals; $(\ddagger) \mathrm{p}<0.05$ with compared with Adh ${ }^{\circledR}$-treated group; (†) $\mathrm{p}<0.05$ compared with GelSp${ }^{\circledR}$-treated group. The Kruskal-Wallis test was used to determine the statistical differences among the four groups during each healing time period. (ns): no significance. 
A

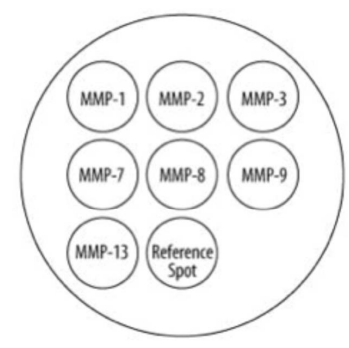

48 hours after surgery

6 days after surgery

18 days after surgery

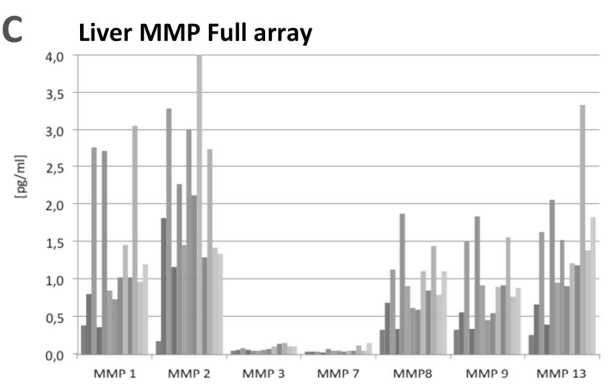

D
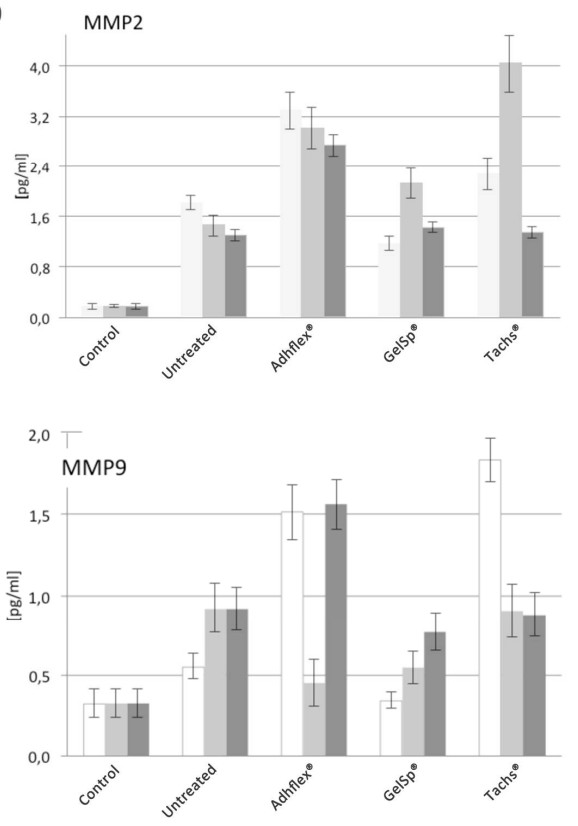

B
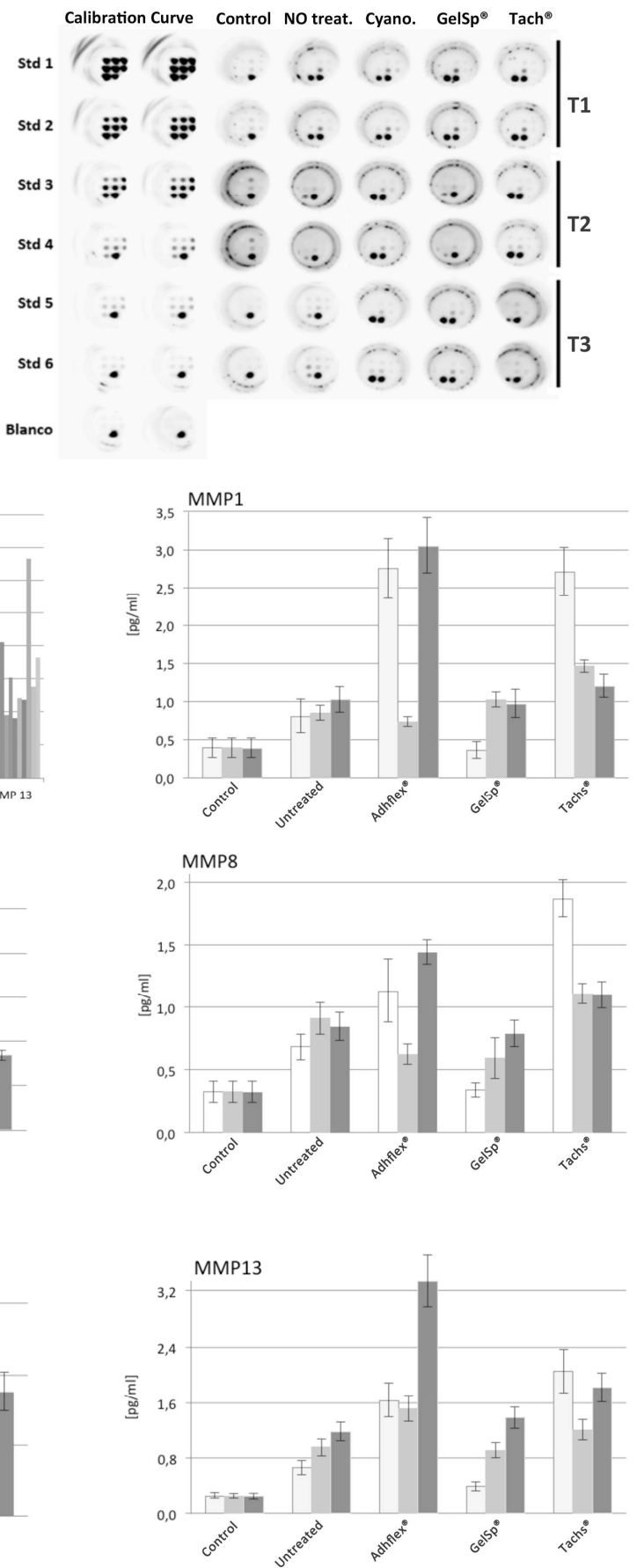

Figure 1. Metalloproteinase expression in sham-control, untreated, and Adhf ${ }^{\circledR}$ and TachS$^{\circledR}$-treated livers. (A) Chart showing the most expressive metalloproteinase; (B) ELISA MMP panel plates (R\&D Systems) of rat metalloproteinase in all groups; (C) Individual graphs for the most expressed metalloproteinases in all groups (control, untreated, and TachS ${ }^{\circledast}$, GelS ${ }^{\circledR}$, and Adhf ${ }^{\oplus}$-treated) tested at 2, 6, and 18 days after surgery and injuries. Mann-Whitney $U$ test: $\left({ }^{*}\right), p<0.05$ as compared to untreated animals; $(\ddagger), \mathrm{p}<0.05$ as compared to $\mathrm{Adhf}^{\circledast}$ group; ( $\dagger$ ), $\mathrm{p}<0.05$ as compared to GelSp ${ }^{\circledast}$ group. The Kruskal-Wallis test was used to determine the statistical differences among four groups in each healing time period. (ns): no significance. 


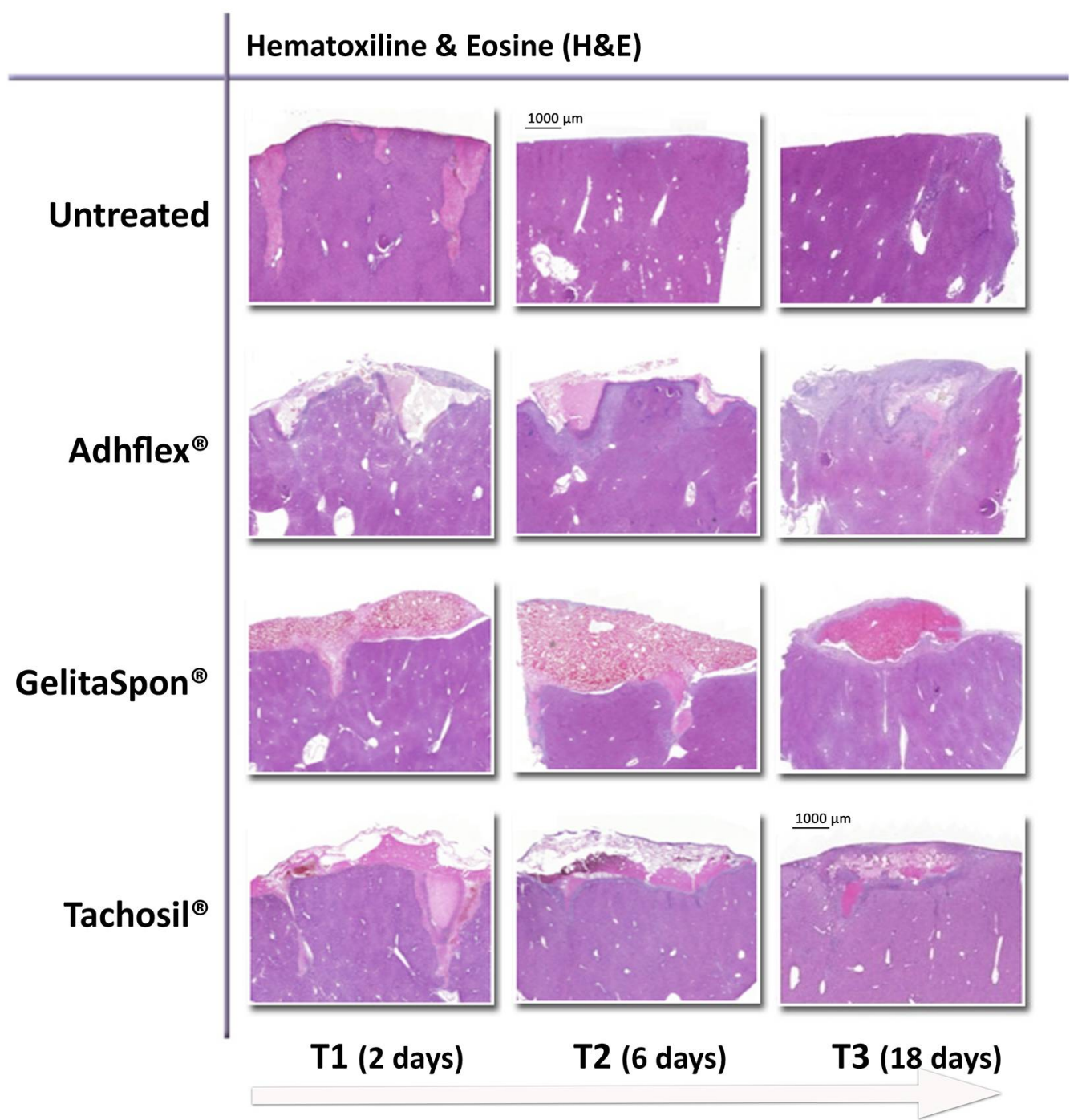

Figure 2. Hematoxylin \& eosin staining (H\&E) panel presenting the evolution of untreated and treated injuries $\left(\mathrm{TachS}^{\circledR}, \mathrm{GelSp}^{\circledR}\right.$, and $\mathrm{Adh}^{\circledR}$ ) in the liver groups.

MMP9: MMP9 exhibited an expression pattern that was nearly identical to that of MMP8. The time since the injury influenced the MMP9 expression in all treated groups, but this was not the case with untreated animals (Table 1). At 18 days post-injury (T3), significant differences were found only between the non-treated group and the animals treated with Adhf $^{\circledR}$. Interestingly, MMP9 expression was lower in the GelSp ${ }^{\circledR}$-treated group than in the untreated group for all times (T1, T2, and T3). As with the other MMPs, the MMP9 expression was highest in the Adhf ${ }^{\circledR}$-treated group, and the difference was statistically significant compared with the other treatments at T3 (18 days) (Table 1, Figure 1). 


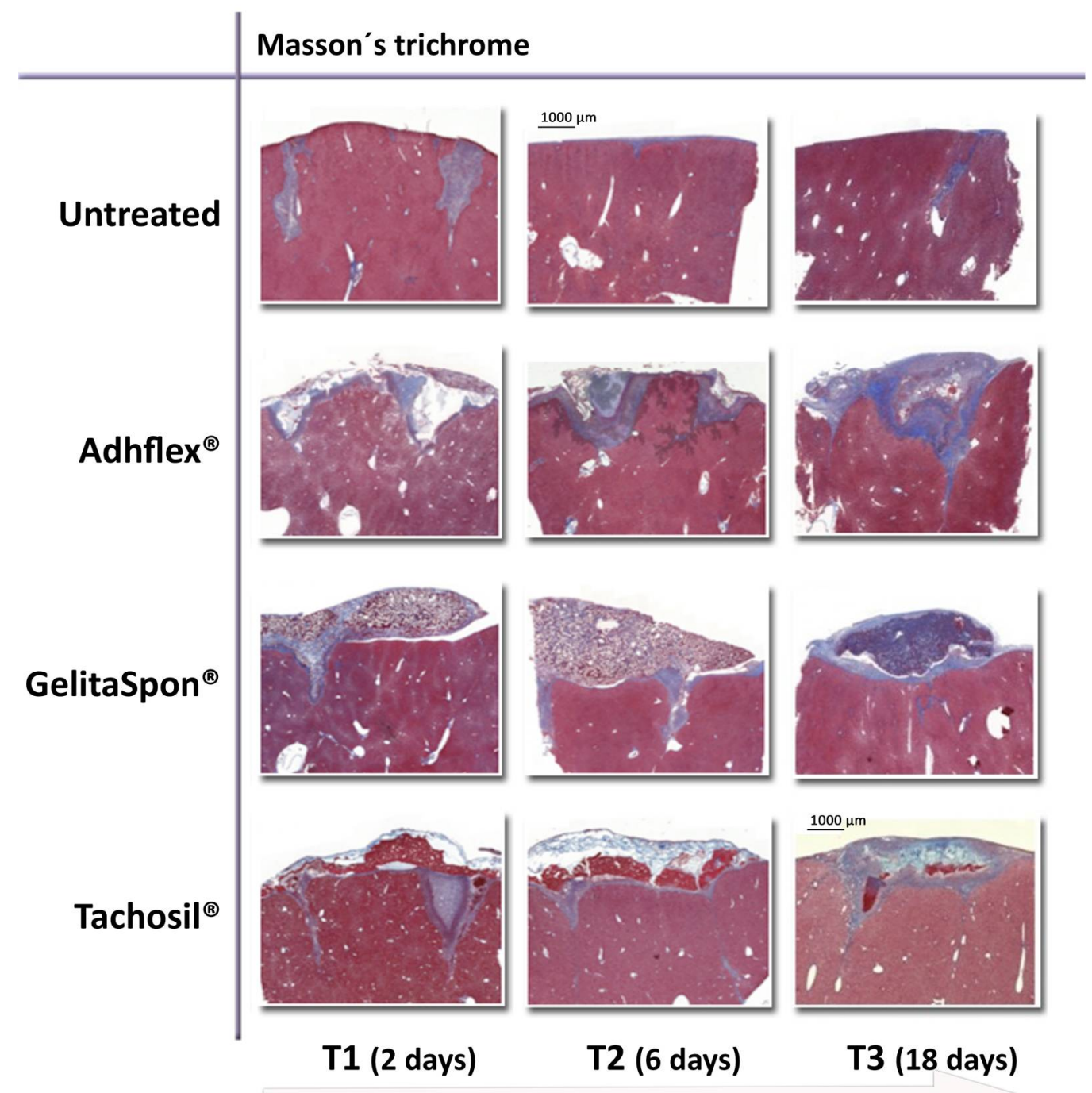

Figure 3. Masson's trichrome staining was used to visualize collagen and reticular fibers. Adhf ${ }^{\circledR}$ generates an inflammatory reaction around the adhesive included in the wound (deep blue mark at the bottom of the lesions (T2 and T3).

\subsection{Histological study}

Figures 2-6 show tissue sections that were stained with hematoxylin and eosin, Masson's trichrome, Periodic Acid Schiff PAS, and immunohistochemical markers CD31 and CD68. Each staining made it possible to observe a different feature of the healing lesions. For all of the tests on the untreated liver lesions, at two days (T1), the wounds produced by the Stiefel biopsy punch were well defined, and there was a dark strip that is compatible with granulation tissue comprising inflammatory cells and fibroblasts. The necrotic tissue had completely disappeared by 18 days post-injury, and the edges of the wound were fully in contact. A column of darkviolet connective tissue could be observed, which corresponded to the injury scar. The parenchyma surrounding the scar had a normal appearance. 


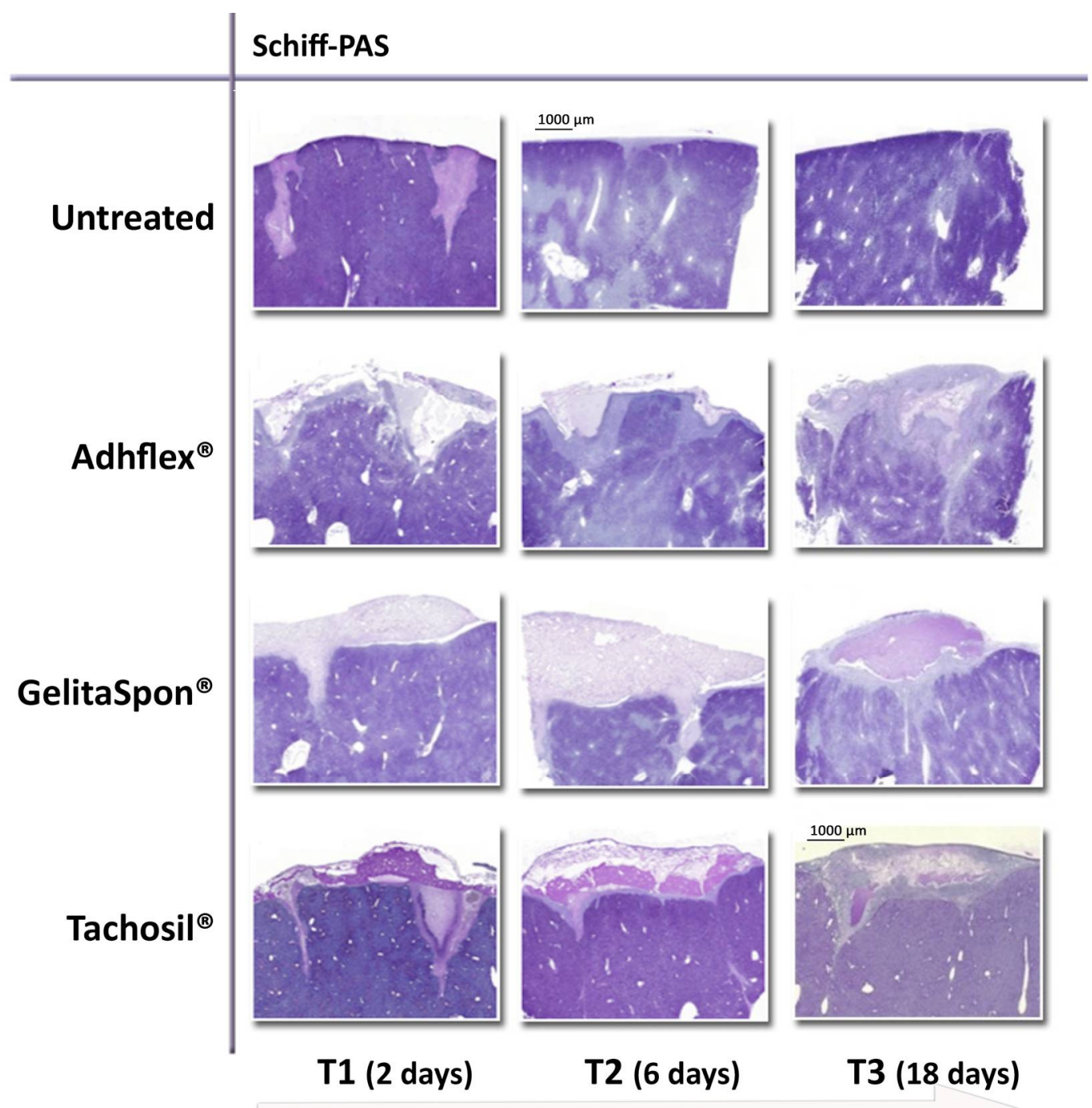

Figure 4. Periodic Acid Schiff (PAS) staining was used to identify glycogen and mucin. The color contrast of the stains reveals each part of the lesions very well, as well as the biomaterials used for wound sealing.

All of the stains were studied to assess the evolution of lesions and the behavior of the sealants used. The lesions were fully healed at 18 days (T3) in the untreated group. In contrast, the treated wounds exhibited traces of biomaterial that adhered to the bottom of the lesions at 18 days. Additional comments are included in the figure captions (Figures 2-6).

The CD31, CD68, and Masson's trichrome staining revealed adhesive traces in the form of lighter areas inside the injury at 18 days after treatment. As they degrade, cyanoacrylates $\left(\mathrm{Adhf}^{\circledR}\right)$ generate aggressive phenolic compounds, which may add to the local inflammatory reaction found in the histological studies of the Adhf ${ }^{\circledR}$-treated group, which appeared to be greater than that found in lesions treated with other sealants (TachS ${ }^{\circledR}$ and GelSp${ }^{\circledR}$ ) (Figures 3, 5, and 6)

\section{Discussion}

The histological healing process of hepatic lesions in response to the three biomaterials was comparable, which has also been described for renal injuries [14]. However, the MMP expression varied with the sealant used. All of the MMPs exhibited higher expression in the 
early stages of the healing process (T1 (2 days)) in animals treated with Adhf ${ }^{\circledR}$ and TachS$^{\circledR}$. Differences between these two sealants were statistically significant for only MMP2 and MMP9, and the expression was higher in the Adhf ${ }^{\oplus}$-treated group. In the case of MMP8 and MPP13, the animals treated with TachS ${ }^{\circledR}$ had significantly higher levels of these MMPs than the Adhf ${ }^{{ }_{-}}$ treated group. Apart from the overexpression of MMPs at the early stages of wound healing, animals treated with Adhf ${ }^{\circledR}$ displayed a maintained overexpression of all of the MMPs tested, even at the latest stages of wound healing (18 days post-injury). Notably, this MMP overexpression did not negatively influence the histological healing process of hepatic injuries.

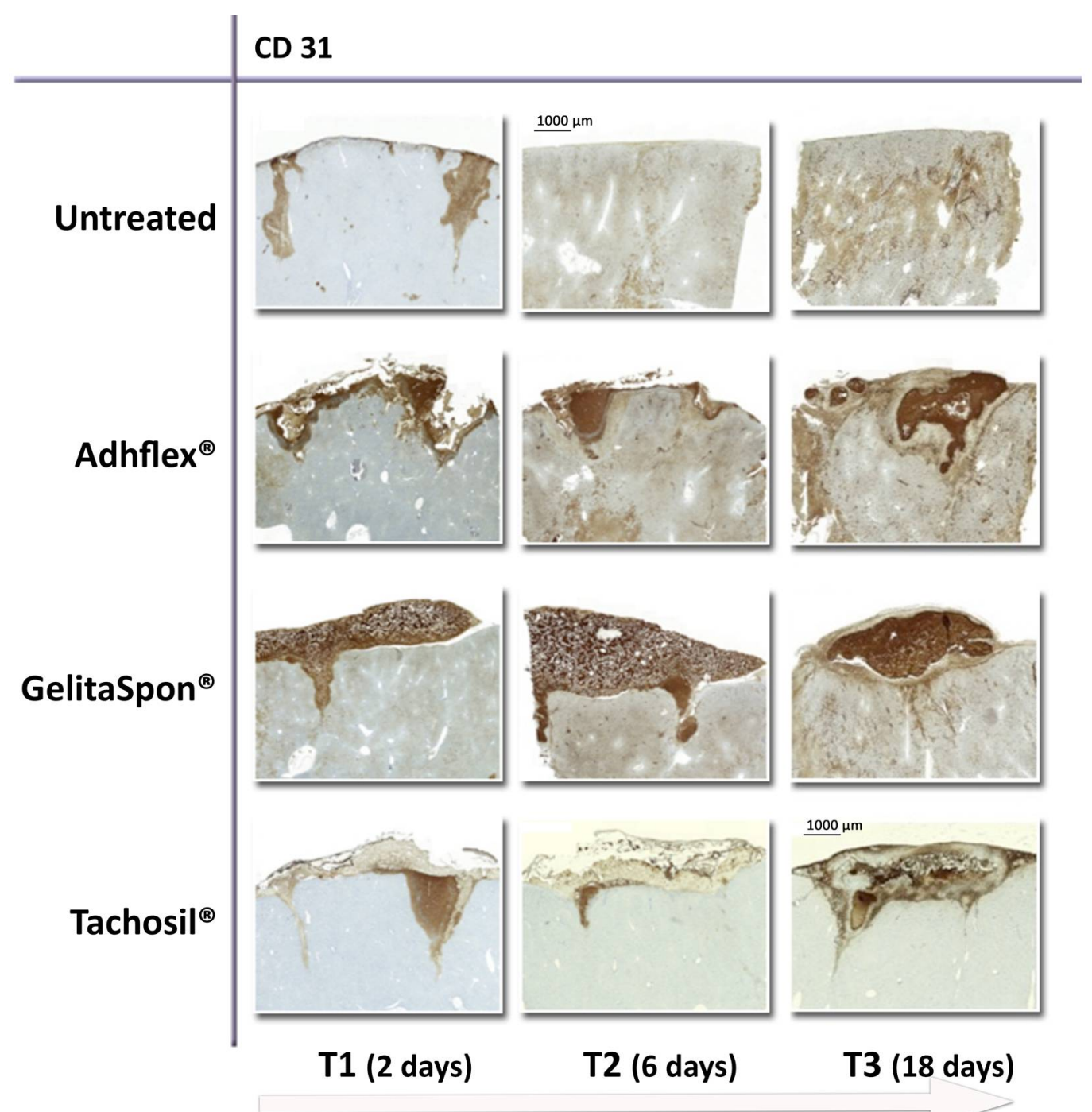

Figure 5. The CD31 immunohistochemical marker is selective for endothelial cells associated with vascular neoformation. The marked wound shows injuries produced by the punch in the untreated group by staining at 2 days (T2). The contact of the materials used to treat the lesion is very well defined in this staining. 


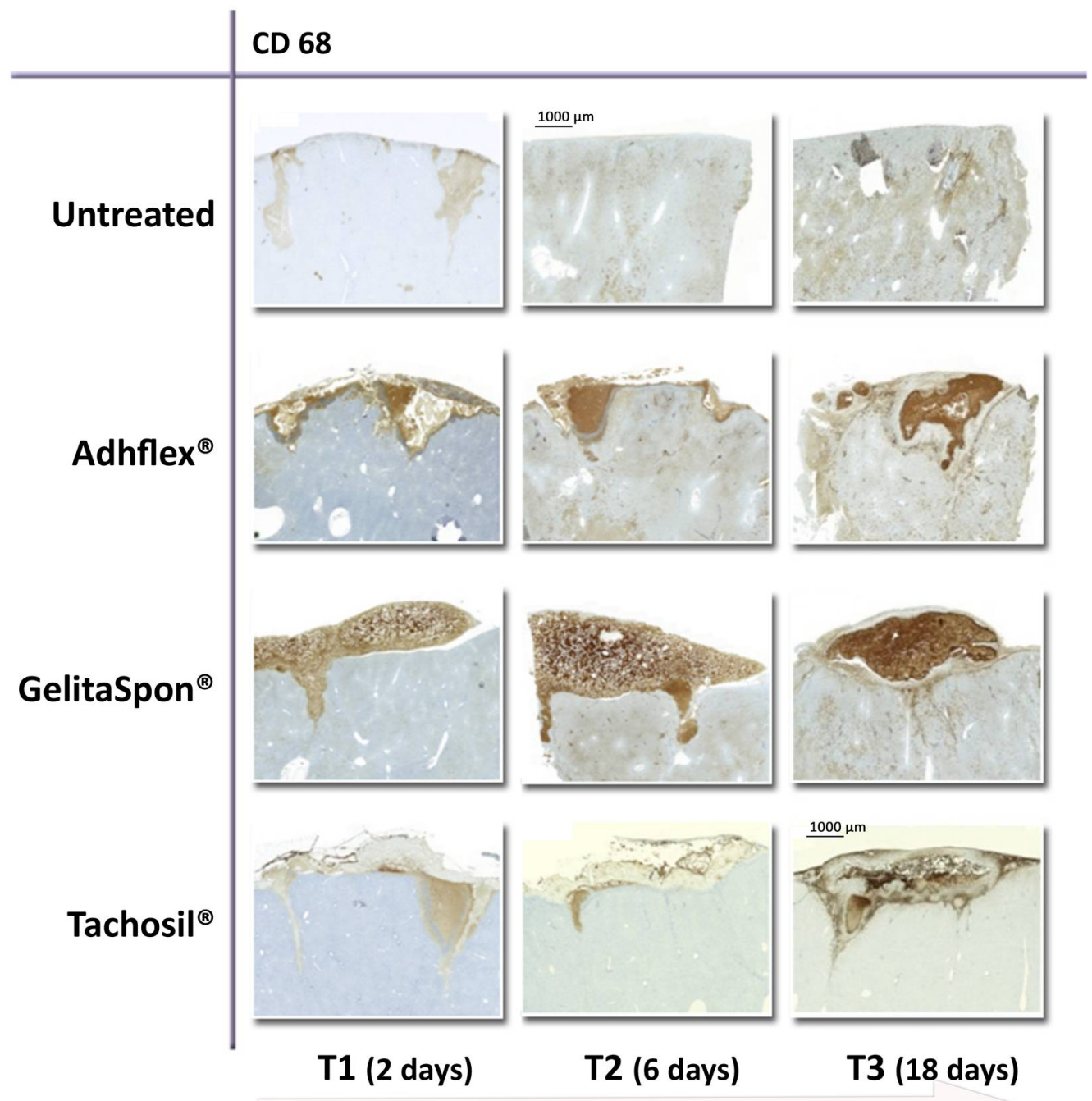

Figure 6. The CD68 marker detects the cytoplasm of mast cells and histiocytes, which are the macrophages present in the post-trauma inflammatory process. The panel images show the contact of the sealants employed and the evolution of wound healing very well, as with the CD31 immunohistochemical marker. Surprisingly, CD86 stained the GelSp ${ }^{\circledR}$ biomaterial strongly, although it was rejected towards the wound edges at the top, even in the image at T1.

Of the MMPs tested, only collagenases (MMP1, MMP8, and MMP13) were able to break down the triple helix of fibrillar collagen. The collagenases had differing expression profiles. MMP1 expression was higher in the groups treated with Adhf ${ }^{\circledR}$ and Tachs ${ }^{\circledR}$ than in the untreated group. The highest MMP1 expression was observed for the Adhf ${ }^{\circledR}$-treated group at 18 days post-injury (Table 1, Figure 1-C). According to the histopathology findings, the high MMP1 values coincide with a persistence of biomaterial in the lesion (Figures 3-6). Therefore, the increased expression of MMP1 might be related to the persistent inflammatory reaction induced by Adhf ${ }^{\circledR}$ at that time of healing. In fact, when an injury becomes chronic, as in the case of dermal ulcers caused by burns, the MMP1 concentration remains high after the first week of healing [25]. Prolonged MMP1 activity in chronic skin ulcers can have a critical effect on the reepithelialization of tissue [26].

Gelatinases (MMP2 and MMP9) play an important role in the formation and maturation of granulation tissue during wound healing [27]. Both MMP2 and MMP9 have been reported to 
act synergistically with collagenases [28]. Once collagenases have cleaved the collagen triple helix, gelatinases begin degrading the Type I, II, and III collagen fibers. MMP2 has been found to delay fibroblast differentiation during healing [29]. Therefore, controlling MMP2 activity could be a way to prevent hypertrophic scarring.

A number of studies have reported increased gelatinase expression following traumatic injury [30,31]. Nessler measured MMP2 expression levels in patients with healing wounds (at 1, 7 , and 25 days post-injury) and found the highest levels at 7 days after the injury [28]. This is in line with other studies, which typically found that MMP expression peaked between day 5 and day 7 post-injury. This coincides with the completion of the inflammatory phase and the formation of granulation tissue [32]. These data are in accordance with the current findings of MMP2 showing significantly higher levels in samples taken 6 days after injury, particularly in TachS ${ }^{\circledR}$-treated animals.

While MMP2 expression is important during the remodeling phase, the gelatinolytic activity of MMP9 appears to be higher in early wound healing. This finding is in line with our findings of MMP9 peak values occurring during the early stage of wound healing in the control group and GelSp ${ }^{\circledR}$-treated group. However, in the Adhf ${ }^{\circledR}$ and Tachs ${ }^{\circledR}$ groups, MMP9 activity remained high at 18 days after injury. The finding that MMP9 expression peaked between 2 and 6 days post-injury may be associated with the normal healing process. The histological findings indicate that $\mathrm{Adhf}^{\circledR}$ and $\mathrm{TachS}^{\circledR}$ treatments yield stronger inflammatory reactions in liver tissue throughout the healing process and possibly contribute to the increased expression of MMP9 of these samples (Figures 3-6).

The predominant role of MMP8 in ECM turnover, the modulation of inflammatory responses, and other physiological processes is well documented [33]. MMP8 is stored in the granules of neutrophils and is released in the first few hours after an injury. Its activity can last up to the end of the inflammatory phase [33-35]. In this study, MMP8 expression peaked at 2 days post-injury in animals treated with TachS ${ }^{\circledR}$ and 18 days post-injury in animals treated with Adhf $^{\circledR}$. In the GelSp${ }^{\circledR}$-treated group, the MMP8 values were below the reference controls during the entire healing process. These MMP8 expression profiles are consistent with a normal healing process.

MMP13 expression was high in all stages of the healing process and was highest in the Adhf ${ }^{\circledR}$-treated group at 18 days. The MMP13 expression was initially higher in the TachS ${ }^{\circledR}$ treated group. The GelSp ${ }^{\circledR}$ sealant did not induce any effect on MMP13 expression. Several studies have pointed out that MMP13 activity in the early stages of healing is beneficial and is associated with the formation of a three-dimensional collagen matrix, as well as with changes in fibroblast morphology and viability [30,36]. MMP13 also influences the activity of myofibroblasts and angiogenesis, particularly when granulation tissue is formed [31]. In spite of such positive effects, high MMP13 expression has also been reported in many chronic skin disorders, as well as other chronic conditions such as rheumatoid osteoarthritis, where it results in destruction of the collagen matrix [36]. The stronger expression of MMP13 in Adhf ${ }^{\circledR}$-treated samples after 18 days may be a consequence of cyanoacrylate remaining at the bottom of the wounds (Figures 3-5).

In regard to the histopathology analyses, the progression of healing was similar for all of the study groups. The application of each individual sealant caused a marked coagulated hematoma in the affected area. Over time, granulation tissue was noticeable around the necrotic area with highly dispersed inflammatory infiltration. The scar tissue initially covered a relatively large surface area in the days following the lesion. However, after 18 days, the size of the scar area decreased significantly (Figure 3). By 18 days post-injury, the necrotic tissue had been eliminated in almost all samples and had been replaced by a strip of connective tissue. This tissue formed a scar and showed signs of contraction, which indicated maturation of the scarred tissue. The healing progress was similar regardless of the sealant used. 
In conclusion, the three sealants used in this study yielded complete healing of the liver lesions. Both the histopathology and MMP findings indicated that the degradation process of Adhf ${ }^{\circledR}$ was slower than that of the other biomaterials and caused a strong initial inflammatory reaction. This can be seen in the histological sections, particularly in CD31, CD68, and Masson's trichrome staining, and the effect has been observed previously in different tissues. However, at the end of the process, the lesions had healed completely. Given that all hepatic trauma injuries should be considered emergencies, any easy-to-use and rapid sealant such as Adhf ${ }^{\circledR}$ could be deemed a suitable treatment option.

\section{Materials and Methods}

4.1. Ethical aspects: The animal welfare procedures and experimental design were approved by the Committee of Animal Welfare (Ethics Committee for Animals Studies) of the Regional Government of Valencia (reference number: VSC/2015/PEA/00097), pursuant to the legislation in force (ref.53/2013 Royal Decree) and FDA recommendations related to welfare of experimental animals.

4.2. Study design : Using an experimental rat model, hepatic injuries were made on the anterior aspect using a Stiefel Biopsy Punch ( $8 \mathrm{~mm}$ diameter, $3 \mathrm{~mm}$ depth), followed by local treatment with either TachS ${ }^{\circledR}, \mathrm{GelSp}{ }^{\circledR}$ or Adhf ${ }^{\circledR}$. An untreated injured group was also included. Wound healing was evaluated 2, 6 and 18 days post-injury.

4.3. Laboratory animals: 90 Wistar rats (body weight: 300-350 g/male) (Harlan Laboratories, Barcelona, Spain) were housed in a standard animal facility, with both pre-operative and postoperative access to food and water. Animal care and surveillance was conducted every 12 hours during the preoperative time and especially all 6 hours in the postoperative period, during 18 days. There were no deaths or illness during the whole period of the experiment

4.4. Groups studied: The rats were divided into: 1 : sham non-injured $(n=3) ; 2$ : untreated group $(n=6) ; 3$ : TachS®-treated group $(n=27) ; 4:$ GelSp$®$-treated $(n=27)$, and 5: Adhf ${ }^{\circledR}$-treated group $(n=27)$. For each group of animals, 4 rats were used for MMP expression and 5 rats were used for histological studies in a follow-up of 3 periods of the study: 2, 6 and 18 days post-injury $(9 \times$ $3=27$ rats). Untreated rats ( 2 animals) were used to study both histology and MMP expression in each study phase $(2 \times 3=6)$.

4.5. Biomaterials and adhesives used: To seal wounds generated by the punch, we use various sealants and adhesives: (TachS®) TachoSil ${ }^{\circledR}$ : haemostatic sponge with human fibrinogen (5.5 mg per $\left.\mathrm{cm}^{2}\right)$ and thrombin $\left(2.0 \mathrm{IU}\right.$ per $\left.\mathrm{cm}^{2}\right)\left(\right.$ Takeda $\mathrm{GmbH}$-Austria) ${ }^{\circledR}$. (GelSp$\left.{ }^{\circledR}\right)$ GelitaSpon ${ }^{\circledR}$ : absorbable, oxidized cellulose sponge (Gelita Medical GmbH-Germany). (Adhf®) Adhflex®: a cyanoacrylate-based adhesive supplemented with acrylates to boost elasticity, reduce stiffness, and enhance cohesive strength (Bioadhesives Medtech Solutions-Spain). Adhf® has a lower polymerization temperature than other cyanoacrylates used in clinical practice and a marked elasticity. All three products possess adhesive and coagulant properties

4.6. Anaesthesia: All animals were anesthetized intraperitoneally (Ketamine $-80 \mathrm{mg} \mathrm{kg}^{-1}$ ) \& (Xylazine -10 $\mathrm{mg} \mathrm{kg}^{-1}$ ) which kept a spontaneous breathing, during a abdominal laparotomy. To control an optimal hematosis, partial $\mathrm{O}_{2}$ and $\mathrm{CO}_{2}$ pressures were monitored, throughout the surgery. For the pain treatment was used (Buprenorphine - $0.1 \mathrm{mg} / \mathrm{kg}$ every $12 \mathrm{~h}$ ) during the first 48 hours after the surgical procedure.

4.7. Standardized treatments: After the anaesthesia, a laparotomy was performed to expose the liver. With direct vision, we performed lesions in the anterior area of the liver with a Stiefel biopsy punch. The selected trocar performed the same lesions $(8 \mathrm{~mm}$ diameter) and depth $(4$ 
$\mathrm{mm}$ ) over the surface with a slight twist. In GelSp ${ }^{\circledR}$ and TachS $®$ groups, wounds were covered with homogeneous circles of the biological adhesives. In Adhf® group, a drop (21.3 $\pm 1.2 \mathrm{mg})$ was applied onto each lesion. To ensure hemorrhagic occlusion, the liver was observed for several additional 3 minutes after sealing the injury. Lastly the abdominal incision was sutured in two layers.

4.8. Euthanasia: On days 2, 6 and 18 post-injury, 9 animals from each group were euthanized by means of an intraperitoneal injection (Sodium pentobarbital - $60 \mathrm{mg} / \mathrm{kg}$ - lethal dose,). The samples were processed for MMP determination and histology.

\subsection{Mealing monitoring:}

4.9.1. Metalioproteinases evolution: During healing, the activation and inhibition of different MMPs have an influence on multiple processes. To test whether or not TachS ${ }, \mathrm{GelSp} \circledast$ or Adhf $®$ favoured local secretion of MMPs by the host hepatic cells, liver homogenates (serum-60 $\mu \mathrm{l})$ were subjected to enzyme-linked immunosorbent assay (ELISA) with MMPs (Mosaic ELISA MMP Panel, R\&D Systems).

Matrix metalloproteinases were quantified via chemiluminescence (as per the manufacturer's instructions). MMP-1, MMP-2, MMP-8, MMP-9 and MMP-13 levels were quantified. Both the panel and the protocol have a sensitivity within the $\mathrm{pg} / \mathrm{ml}$ range. MMP levels were quantified by means of gel densitometry (Image J), using the mean of duplicate samples. Equal spot sizes were studied per blot. The Mosaic ELISA MMP Panel can detect up to 7 different MMPs. Yet, due to sensitivity limitations, our analyses were solely focused on the most strongly expressed MMPs.

4.9.2. Histological studies: Haematoxylin-Eosin staining ( $3 \mu \mathrm{m}$ thick slices) was utilized for the samples study. Specific stains were used in order to identify histological changes caused in the development of hepatic lesions and the effects of several treatments. Five liver tissue samples from each group were examined. Masson's trichrome staining protocol was used to visualize collagen and reticular fibers, highlighting the increased apposition of collagen at the time of healing. [35] Periodic Acid Schiff (PAS) staining was used to identify glycogen and mucin. [36] Five liver tissue samples from each group were examined. The CD31 immunohistochemical marker is selective for endothelial cells associated with vascular neoformation. [37] The CD68 marker detects a glycoprotein (approximately $110 \mathrm{kD}$ ) in the cytoplasm of mast cells and histiocytes, which are macrophages present in the post-trauma inflammatory process. [38]

4.10. Statistical analysis: SPSS Statistics (v. 20.0, IBM-NY, USA) was used in all of the statistical analyses. Fisher's Least Significant Difference (LSD) test was applied to identify significant inter-group differences $(\mathrm{p}<0.05)$ in the size of the gap between wound edges. Given the small sample size of our rat cohort, we used the non-parametric Kruskal-Wallis test to compare differences in MMP expression across groups. The Mann-Whitney $U$ test was used to study differences in MMP expression between the untreated group and each treated group. $P$-values under 0.05 were considered to be statistically significant. Normality and Levene's test were used to assess the equality of error variance for each variable.

Acknowledgments: The authors wish to thank the Institute of Pathology headed by Professor Jerónimo Forteza.

Author Contributions: Lloris JM: conceptualization, methodology, supervision, writing - original draft; Barrios C: data curation, investigation, methodology, validation, writing-review \& editing; Lloris- 
Cejalvo : methodology, proyect administration, resources; Lloris-Salvi: data curation, format analysis, validation; Cejalvo-Lapeña : conceptualization, data curation,, investigation, writing-review\& editing

Conflicts of Interest: The authors alone are responsible for the content and writing of the paper. The authors declare no conflict of interest.

Financial support: No funding was received for this work

\section{References}

1. Lacaze L, Le Dem N, Bubenheim M, Tsilividis B, Mezghani J, Schwartz L, Francois A, Ertaud JY, Bagot d'Arc M, Scotté M. Tensile strength of biological fibrin sealants: a comparative study. J Surg Res. 2012 Aug;176(2):455-9

2. Koea JB, Batiller J, Aguirre N, Shen J, Kocharian R, Bochicchio G, Garden OJ. A multicentre, prospective, randomized, controlled trial comparing EVARREST ${ }^{\mathrm{TM}}$ fibrin sealant patch to standard of care in controlling bleeding following elective hepatectomy: anatomic versus non-anatomic resection. HPB (Oxford). 2016 Mar;18(3):221-8.

3. You KE, Koo MA, Lee DH, Kwon BJ, Lee MH, Hyon SH, Seomun Y, Kim JT, Park JC.The effective control of a bleeding injury using a medical adhesive containing batroxobin. Biomed Mater. 2014 Apr;9(2):025002.

4. Esposito C, Damiano R, Settimi A, De Marco M, Maglio P, Centonze A. Experience with the use of tissue adhesives in pediatric endoscopic surgery. Surg Endosc. 2004 Feb;18(2):290-2. Epub 2003 Dec 29.

5. Martin-Mateos RM, Lopez-San Roman A, García-Sánchez C, Garcia-Hoz F, Gil-Grande LA, Gómez EG, García-González M. Fibrin-glue-sealed liver biopsy: indications, complications and results. J Gastrointestin Liver Dis. 2014 Mar;23(1):100-1

6. Duarte S, Baber J, Fujii T1, Coito AJ.Matrix metalloproteinases in liver injury, repair and fibrosis. Matrix Biol. 2015 May-Jul;44-46:147-56.

7. Sheets AR, Massey CJ, Cronk SM, Iafrati MD, Herman IM (2016) Matrix- and plasmaderived peptides promote tissue-specific injury responses and wound healing in diabetic swine. J Transl Med 2;14(1):197.

8. Tokito A, Jougasaki M (2016) Matrix Metalloproteinases in Non-Neoplastic Disorders. Int J Mol Sci 21;17(7).

9. Kang YM, Hong SH, Yang JH, Oh JC, Park JO, Lee BH, Lee SY, Kim HS, Lee HM, Moon SH (2016) Pamidronate Down-regulates Tumor Necrosis Factor-alpha Induced Matrix Metalloproteinases Expression in Human Intervertebral Disc Cells. J Bone Metab 23(3):165-73.

10. Consolo M, Amoroso A, Spandidos DA, Mazzarino MC (2009) Matrix metalloproteinases and their inhibitors as markers of inflammation and fibrosis in chronic liver disease (Review). Int J Mol Med. 24(2):143-52.

11. Yamamoto K, Murphy G, Troeberg L (2015) Extracellular regulation of metalloproteinases. Matrix Biol. 44-46:255-63.

12. C. Bonnans, J. Chou, Z. Werb. Remodeling the extracellular matrix in development and disease. Nat. Rev. Mol. Cell Biol., 2014;15: 786-801 
13. Gibson DJ, Schultz GS.(2013) Molecular Wound Assessments: Matrix Metalloproteinases. Adv Wound Care (New Rochelle). 2(1):18-23.

14. Utz ER, Elster EA, Tadaki DK, Gage F, Perdue PW, Forsberg JA, et al.: Metalloproteinase expression is associated with traumatic wound failure. J Surg Res 2010; 159: 633-638

15. Dos Santos OJ, de Souza G, Sauaia EN, Medeiros G, Pinheiro RH, Pinheiro RA (2012) Use of 2-octyl-cyanoacrylate adhesive in rat liver induced lesion. Act Cir Bras. 27(9): 624-9.

16. Dávila F, Islas HG, Carbonell JM, Hernández LM, Sánchez DJ, Rivera JM (2009) Uso del 2 cianoacrilato de $\mathrm{N}$-butilo en la reparación primaria de heridas penetrantes en hígado, bazo e intestino delgado: modelo experimental en perros. Rev Sanid Milit Mex. 63(4): $182-8$

17. Amălinei C1, Căruntu ID, Giuşcă SE, Bălan RA. Matrix metalloproteinases involvement in pathologic conditions. Rom J Morphol Embryol. 2010;51(2):215-28.

18. Hemmann S1, Graf J, Roderfeld M, Roeb E.Expression of MMPs and TIMPs in liver fibrosis - a systematic review with special emphasis on anti-fibrotic strategies. J Hepatol. 2007 May; 46 (5) :955-75.

19. Lloris-Carsí JM, García-Cerdá D, Prieto-Moure B, Barrios C, Martín-Ballester AB, Cejalvo-Lapeña D. (2016) Behaviour of the Biological Adhesives TachoSil ${ }$, GelitaSpon ${ }^{\circledR}$, and a New Elastic Cyanoacrylate (Adhflex ${ }^{\circledR}$ ) in Experimental Renal Trauma and Wound Healing. Eur Surg Res.56(3-4):164-79.

20. Lloris-Carsí JM, Ballester-Álvaro J, Barrios C, Zaragozá-Fernández C, Gómez-De la Cruz C, González-Cuartero C, Prieto-Moure B, Cejalvo-Lapeña D. (2016) Randomized clinical trial of a new cyanoacrylate flexible tissue adhesive (Adhflex) for repairing surgical wounds. Wound Repair Regen. 24(3):568-80.

21. Landegren $\mathrm{T}$, Risling $\mathrm{M}$, Persson JK. Local tissue reactions after nerve repair with ethylcyanoacrylate compared with epineural sutures. Scand I Plast Reconstr Surg Hand Surg. 2007;41(5):217-27.

22. Nursal TZ, Anarat R, Bircan S, Yildirim S, Tarim A, Haberal M. The effect of tissue adhesive, octyl-cyanoacrylate, on the healing of experimental high-risk and normal colonic anastomoses. Am J Surg. 2004 Jan;187(1):28-32.

23. Li H, Nahas Z, Feng F, Elisseeff JH, Boahene K (2013) Tissue engineering for in vitro analysis of matrix metalloproteinases in the pathogenesis of keloid lesions. JAMA Facial Plast Surg. 15(6):448-56

24. Beidler SK, Douillet CD, Berndt DF, Keagy BA, Rich PB, Marston WA (2008) Multiplexed analysis of matrix metalloproteinases in leg ulcer tissue of patients with chronic venous insufficiency before and after compression therapy. Wound Repair Regen. 16(5):642-8

25. Inkinen $\mathrm{K}$, Trakainen $\mathrm{H}$, Wolf $\mathrm{H}$, Ravanti L, Kähäri, VM, Ahonen J. Expression and activity of matrix metalloproteinase- 2 and -9 in experimental granulation tissue. APMIS 2000; 108:318-328.

26. Nessler MB, Puchata J, Chrapusta A, Nessler K, Drukata J (2014) Levels of plasma matrix metalloproteinases (MMP-2 and MMP-9) in response to INTEGRA ${ }^{\circledR}$ dermal regeneration template implantation. Med Sci monit. 20:91-96. 
27. Hata S, Okamura K, Hatta M, Ishikawa H, Yamazaki J (2014) Proteolytic and Nonproteolytic Activation of Keratinocyte-Derived Latent TGF-B1 Induces Fibroblast Differentiation in a Wound-Healing Model Using Rat Skin. J Pharmacol Sci.124:230-243.

28. Toriseva M, Kähäri VM (2009) Proteinases in cutaneous wound healing. Cell Mol Life Sci. 66:203-224.

29. Toriseva M, Laato M, Carpen O, Ruohonen ST, Savontaus E, Inada M, Krane SM, Kähäri VM (2012) MMP-13 Regulates Growth of Wound Granulation Tissue and Modulates Gene Expression Signatures Involved in Inflammation, Proteolysis, and Cell Viability. PLoSONE 7(8): e42596.

30. Stern R, McPherson M, Longaker MT (1990) Histologic study of artificial skin used in the treatment of full-thickness thermal injury. J Burn Care Rehab. 11(1):7-13.

31. Dejonckheere E1, Vandenbroucke RE, Libert C. Matrix metalloproteinase8 has a central role in inflammatory disorders and cancer progression. Cytokine Growth Factor Rev. 2011 Apr;22(2):73-81.

32. Danielsen PL, Holst AV, Maltesen HR, Bassi MR, Holst PJ, Heinemeier KM, Olsen J, Danielsen CC, Poulsen SS, Jorgensen LN, Agren MS (2011) Matrix metalloproteinase-8 overexpression prevents proper tissue repair. Surgery.150(5):897-906

33. Aström P, Pirilä E, Lithovius R, Heikkola H, Korpi JT, Hernández M, Sorsa T, Salo T (2014) Matrix metalloproteinase-8 regulates transforming growth factor- $\beta 1$ levels in mouse tongue wounds and fibroblasts in vitro. Exp Cell Res. 15;328(1):217-27

34. Toriseva M, Ala-aho R, Karvinen J, Baker AH, Marjomaki VS, et al. (2007) Collagenase-3 (MMP-13) engances remodeling of three-dimensional collagen and promotes survival of human skin fibroblasts. J Invest Dermatol. 127:49-59.

35. Ahn HB, Shin DM, Roh MS, Jeung WJ, Park WC, Rho SH. A comparison of 2-octyl cyanoacrylate adhesives versus conventional suture materials for eyelid wound closure in rabbits. Korean J Ophthalmol. 2011; 25(2): 121-127.

36. Feng CC, Wang LJ, Zhou ZW, Ding Q, Fang ZJ, Xia GW, Jiang HW, Xu G, Wen H. Positive KI67 and periodic acid-schiff mandates wider range of excision in scrotal extramammary Paget's disease. Dermatol Surg. 2013; 39(3): 381-386.

37. DeYoung BR, Swanson PE, Argenyi ZB, Ritter JH, Fitsgibbon JF, Stahl DJ, Hoover W, Wick MR. CD31 immunoreactivity in mesenchymal neoplasms of the skin and subcutis: Report of 145 cases and review of putative immunohistologic markers of endothelial differentiation. J Cutan Pathol. 1995; 22(3): 215-222.

38. Goyert SM. MC12. CD68 workshop panel report. In: Kishimoto T, Kikutani H, von dem Borne AEG, Goyert SM, Mason DY, Miyasaka M, et al., editors. Leucocyte typing VI. White cell differentiation antigens. Proceedings of the 6th International Workshop and Conference; 1996 Nov 10-14; Kobe, Japan. New York, London: Garland Publishing Inc.; 1997. p. 1015-1016. 